\title{
Reversing the Trend of Large Scale and Centralization in Manufacturing: The Case of Distributed Manufacturing of Customizable 3-D-Printable Self-Adjustable Glasses
}

\author{
Jephias Gwamuri ${ }^{1,2}$, Ben T. Wittbrodt ${ }^{1,2}$, Nick C. Anzalone ${ }^{1}$, Joshua M. Pearce ${ }^{1,2,3, *}$ \\ ${ }^{1}$ The Michigan Tech Open Sustainability Technology (MOST) Laboratory, 601 M\&M Building, 1400 Townsend \\ Drive, Houghton, MI 49931-1295, United States; E-Mail: jgwamuri@mtu.edu (JG), btwittbr@mtu.edu (BTW), \\ nick@anzalonemail.com (NCA) \\ ${ }^{2}$ Department of Materials Science \& Engineering, Michigan Technological University, 601 M\&M Building, 1400 \\ Townsend Drive, Houghton, MI 49931-1295, United States \\ ${ }^{3}$ Department of Electrical \& Computer Engineering, Michigan Technological University, 601 M\&M Building, 1400 \\ Townsend Drive, Houghton, MI 49931-1295, United States
}

* Corresponding Author: E-Mail: pearce@mtu.edu; Tel.: +19064871466

Submitted: 29. May 2014 | In revised form: 22. August 2014 | Accepted: 22. October 2014 |

Published: 12 December 2014

\begin{abstract}
Although the trend in manufacturing has been towards centralization to leverage economies of scale, the recent rapid technical development of open-source 3-D printers enables low-cost distributed bespoke production. This paper explores the potential advantages of a distributed manufacturing model of high-value products by investigating the application of 3-D printing to self-refraction eyeglasses. A series of parametric 3-D printable designs is developed, fabricated and tested to overcome limitations identified with mass-manufactured self-correcting eyeglasses designed for the developing world's poor. By utilizing 3-D printable self-adjustable glasses, communities not only gain access to far more diversity in product design, as the glasses can be customized for the individual, but 3-D printing also offers the potential for significant cost reductions. The results show that distributed manufacturing with open-source 3-D printing can empower developing world communities through the ability to print less expensive and customized self-adjusting eyeglasses. This offers the potential to displace both centrally manufactured conventional and self-adjusting glasses while completely eliminating the costs of the conventional optics correction experience, including those of highly-trained optometrists and ophthalmologists and their associated equipment. Although, this study only analyzed a single product, it is clear that other products would benefit from the same approach in isolated regions of the developing world.
\end{abstract}

Keywords: additive layer manufacturing; development; distributed manufacturing; eye care; glasses; 3-D printing

(C) 2014 by the authors; licensee Librello, Switzerland. This open access article was published under a Creative Commons Attribution License (http://creativecommons.org/licenses/by/3.0/). 


\section{Introduction}

The history of mass production predates the industrial revolution and was initially motivated by the need to equip large armies with standardized weapons, but by the end of the 19th century the production of large amounts of standardized products on assembly lines became widespread and central to economics [1-3]. The benefits of large-scale manufacturing (or flow production) are well established and include reduction in costs due to the economies of scale from: i) bulk purchasing of materials, supplies, and components through long-term contracts; ii) technological advantages of returns to scale in the production function, such as lower embodied energy during manufacturing of a given product because of scale; iii) favorable financing in terms of interest, access to capital and a variety of financial instruments; iv) marketing and v) increased specialization of employees and managers [4-6]. These advantages have created a general trend towards large-scale manufacturing in low-labor cost countries, especially for inexpensive plastic products $[7,8]$.

Centralized and mass manufactured goods are often still unaffordable to remote communities of the developing world because of proportionally large distribution and transportation costs [9]. These transportation costs have a concomitant embodied energy and environmental impact of transportation that can be substantial [10]. Centralized manufacturing, thus is deficient in two fronts; cost in the developing world and environmental impact. A sustainable manufacturing system with optimized value calls for a broader and more holistic view than lowest unit cost of production and points to the potential for distributed manufacturing systems encompassing engineeringmanagement aspects, economic and technical issues, environmental drivers and social implications $[11,12]$. Until recently there was no technology capable of providing the necessary low costs and the ability to be distributed to isolated regions.

3-D printing offers a novel form of localized and customized production and is an emerging 21st century innovation platform for promoting distributed manufacturing systems [13-18]. The technological development of additive manufacturing with 3-D printers has been substantial $[15,16]$, which has benefited many industries; however, the costs of 3-D printers have historically been too high to be feasible for distributed or home-based manufacturing [19]. Recently, several open-source (OS) models of commercial rapid prototypes have been developed [19], which offer an alternative model of low-cost production. The most successful of these is the self-replicating rapid prototype (RepRap), which can be built from 3-D printed parts, open-source electronics, and common hardware for about $\$ 500[20,21]$. Using computer aided design (CAD) customized (shapes and designs) prototypes can be produced quickly and economically
[22] and there is evidence the RepRap can fabricate products less expensively than conventional manufacturing [23]. Distributed manufacturing using low-cost open-source 3-D printers has been shown to generally have the potential of reducing the environmental impact, in particular for plastic products $[14-17,24]$ as the nature of 3-D printing allows for the minimization of production waste while maximizing material utilization $[19,25,26]$. Furthermore, distributed manufacturing in the form of open-source appropriate 3-D printing technology, combined with distributed generation (solar photovoltaic powered 3-D printers), has the potential to alleviate poverty in impoverished rural communities in the developing world [18].

This paper explores the potential advantages of a distributed manufacturing model of high-value products by investigating eyeglasses, which are currently only mass-manufactured for the reasons detailed above. Specifically, this paper reports on a case study of 3-D printable self-adjustable glasses by first reviewing the potential market for low-cost corrective glasses and then the limitations of centrally mass-manufactured self-adjustable glasses. Then a series of parametric 3-D printable designs is developed to overcome each of the identified limitations as a proof of concept. The results are analyzed for this case study and conclusions are drawn about the potential reversal of the manufacturing trend of centralization.

\section{Case Study}

The World Health Organization (WHO) estimates that globally about 314 million people are visually impaired, of whom 45 million are blind [27]. The WHO predicts that $80 \%$ of all visual impairment is avoidable (can be prevented or cured). The global distribution of avoidable blindness based on the population in each of the WHO regions is: South East Asian 28\%, Western Pacific 26\%, African 16.6\%, Eastern Mediterranean $10 \%$, American 9.6\%, and European 9.6\% [27]. With almost $90 \%$ of blind and visually impaired people living in low- and middle-income countries, including some of the world's poorest communities, access to eye care is often unavailable $[27,28]$. Globally 153 million people over 5 years of age are visually impaired as a result of uncorrected refractive errors (URE) [29].

Conventional approaches to correcting URE are firmly rooted in the health-care sector and involve having an eye care professional perform an eye examination to determine the general health of the eye and whether eyeglasses are required to improve vision [30]. Correcting URE requires both specialized complex equipment and professional eye specialistsophthalmologists, optometrists/refractionists and opticians-to implement effectively. However, access to eye care and hence eyeglasses is severely limited in the developing world due to an acute lack of professionals and financial resources to provide adequate 
eye care services. For some cases in Africa: South Africa has approximately 2400 eye care practitioners servicing a population of roughly 47 million people [30] a ratio of approximately 1:20,000 whilst in Ghana the ratio of trained eye care professionals to members of the public is $1: 200,000[31,32]$ and approximately $1: 1,000,000$ for the case of Ethiopia [30]. These ratios are far less than the WHO recommended standard for 2010 of one refractionist per 100,000 population [27]. The African WHO region with 70.5 million estimated cases of vision impairment due to uncorrected refraction errors have a total of 4,985 existing functional clinical refractionist and thus requires an additional 10,138 [33]. Similarly, the South-east Asia region (196.2 million visual impairment cases) has 12,415 existing functional refractionist requiring an additional 21,651 [33]. Using a conventional approach this would require over $\$ 2,000$ million for training the additional personnel and establishing new refraction care facilities over a 5 year period in Africa, and over $\$ 3,450$ million for South-east Asia for the same period of time [33]. A full functional practice requires clinical refractive equipment, ocular health screening equipment, ophthalmic dispensing equipment and accounting and business equipment as well as the cost of start-up stock [33]. The Digital Refraction Systems alone can cost well in excess of $\$ 33,000$ and ophthalmic dispensing equipment prices can be well over $\$ 10,000$ [34]. Therefore, to establish a facility with basic equipment can cost over $\$ 100,000$. Automated refraction requires access to expensive machines, which must be adequately maintained and calibrated and are mostly unsuitable for remote off-the grid communities and hence not a viable option. The ratio of ready-made to custom-made spectacles can be assumed to be 20 to 80 , which is in line with expectations in the developed world $[33,35]$. Current market prices for ready-made prescription eyeglasses range from less than $\$ 7$ online to over $\$ 1,000$ from the optometrist [36]. This eyeglass price is currently beyond the budget of many developing world communities whose cost of living is less than a $\$ 1.25$ per day. According to the World Bank report, more than 1.22 billion people in the developing world are living below this extreme poverty baseline [37].

The general steps in the provision of refraction services [27] can be summarized as in Figure 1.

A potential solution to this problem is self-refraction through the use of Silver's revolutionary self-adaptive eyeglasses [38,39]. Adjustable eyeglasses (Adspec lens/glasses) offer the user the ability to change the power of each adaptive lens independently to improve vision in each eye: a process known as self-refraction, a potential solution to the shortfall in eye care profes

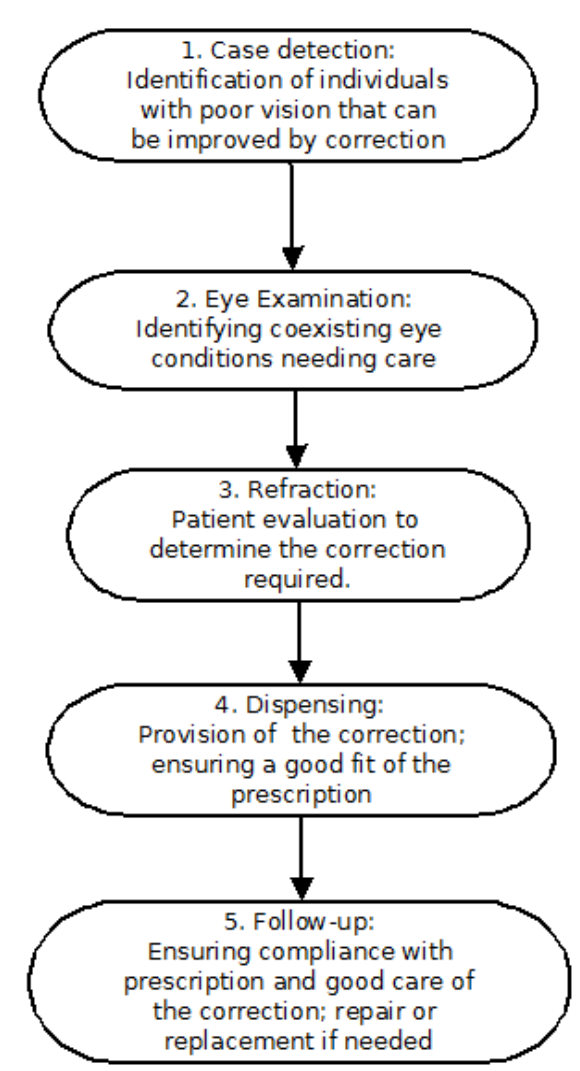

Figure 1. The general steps in the provision of refraction service.

sionals in developing countries. Self-adjusting eye glasses thus provide a means of both measuring and correcting refractive error in regions underserved by eye care professionals. The use of wearer adjustable eyeglasses solves two problems: first, it reduces the need for measurement by a trained refractionist, which is crucial for regions with few eye care professionals. Secondly, it offers a much simpler and far cheaper deployment compared to a more conventional approach based on lens grinding or stock optics [30,38-42]. Self-adjusting eyeglasses would make vision correction accessible particularly to those in the developing world where there is either a lack of professionally trained optometrists and ophthalmologists, or where the cost of traditional spectacle lenses and professional consultation is prohibitively expensive [42].

The Adspec lens is composed of two thin circular membranes sealed at the edges and filled with a fluid with an index of refraction, $n$, of 1.579 [42]. The optical power of the lens is a function of the surface curvature, which is determined by the volume of the fluid in between the membranes. Hence by varying the fluid volume, the optical power of the lens can also be varied to the desired value. Mounting two adaptive lens on a specialized spectacle frame results 
in an adaptive spectacles (Adspecs) [42], which offers the user to ability to adjust the refractive power of each lens to achieve self-refraction. The useful power range of the lenses was reported to be $-6 D$ to $+12 D$ [42]. Preliminary field trials to determine the effectiveness of the Adspec lenses as a means of vision correction were performed both in selected African and Asian countries with promising results [38-43]. Vision correction using self-adjusting spectacles can be summarized as in Figure 2.

Adspecs have the potential for achieving Vision 2020; a partnership between the World Health Organization (WHO) and the International Agency for the Prevention of Blindness (IAPB) launched in 1999 with the twin aims of eliminating avoidable blindness by the year 2020 and preventing the projected doubling of avoidable visual impairment between 1990 and $2020[27,28]$. Adspec technology can be considered a great success, however, the deployed Adspecs have four remaining challenges: 1) the frame is highly fragile, which makes it potentially inappropriate for children and adults whose job involves manual labor (see Figure 3 ), 2) the costs are too high for target communities with low incomes, 3) people of different age, gender, ethnicity and geographical locations have variable widths between their eyes, which does not allow a one-size-fits all mass manufacturing of Adspecs, and 4) they are not aesthetically appealing and socially acceptable for many teenagers (i.e. they are not cool). The first generation of Adspecs tended to break at the hinge and users would use duct tape to make them operational as seen in Figure $3 a$ and $3 b$, which did not assist with aesthetics and long term use.

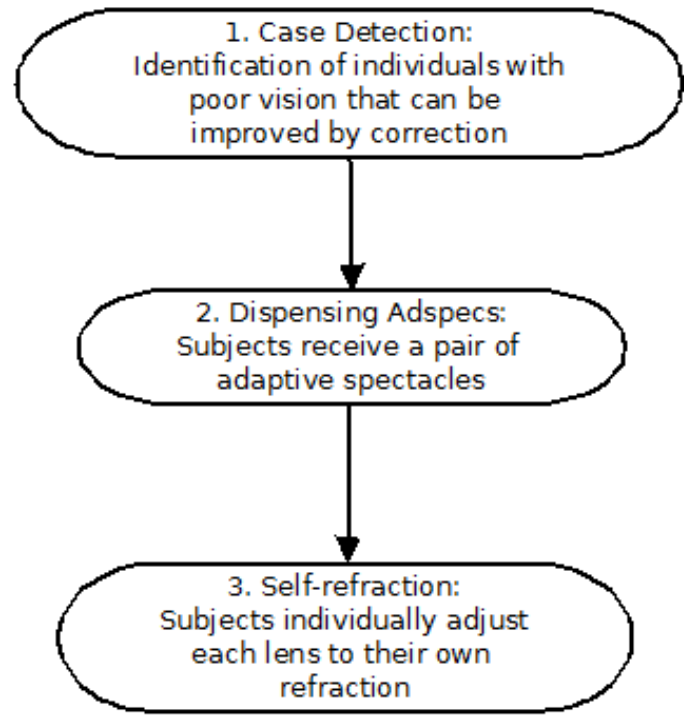

Figure 2. Adaptive spectacles self-refracting procedure.
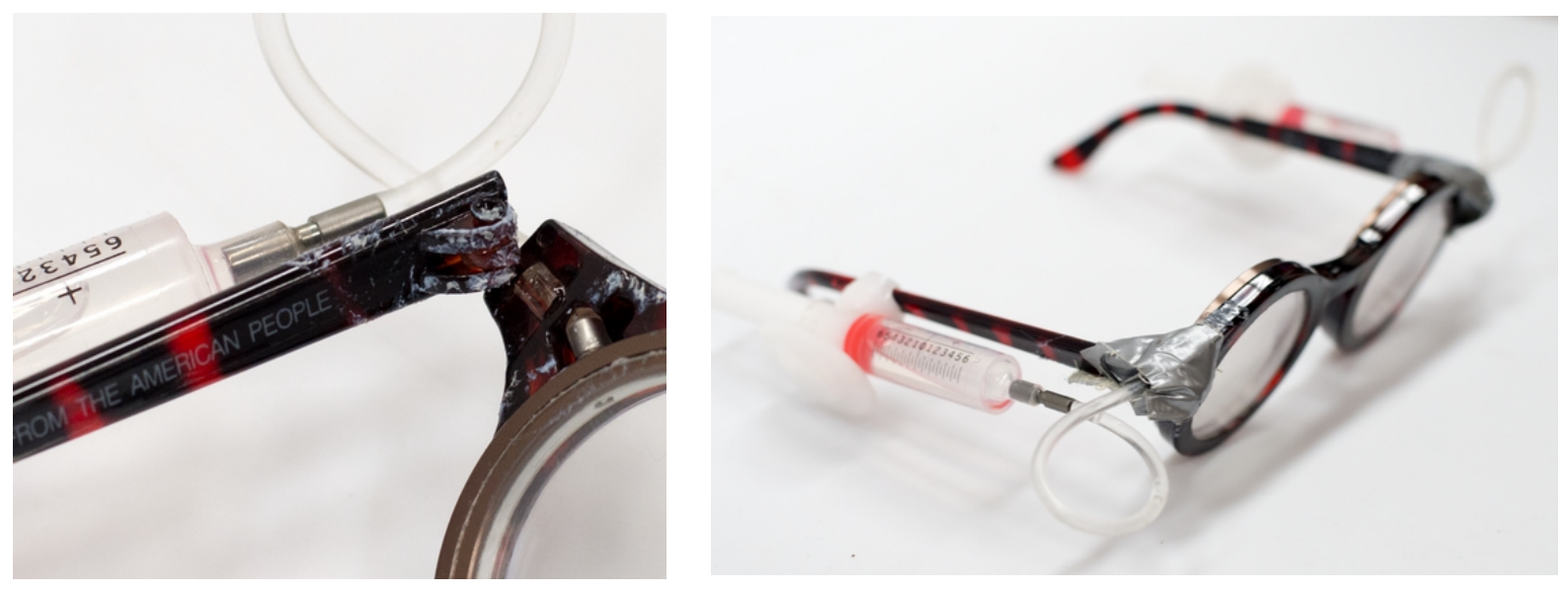

Figure 3. a) Detail of hinge break on an Adspec lense and b) the Adspec system fixed with duct tape.

The use of open source appropriate techniques (OSAT) [44] such as open source 3-D printing has the potential to solve all four challenges. The first problem can be easily overcome by varying the thickness, printing density or combining different materials to achieve the desired strength at the hinge. Second, cost reductions of up-to $95 \%$ have been demonstrated for the open source 3-D printing of optics equipment [45] and the 3-D printing of common household products has been shown to be substantially lower than mass manufacturing retail costs, neglecting additional shipping and tax charges [23]. One major advantage of distributed fabrication is the ability to customize the products to meet specific individuals' or groups' needs. Customization provides the flexibility to selectively fabricate eyeglass frames to each individual's taste and eye spacing making the self-adjusting spectacles both appealing and comfortable to wear, solving challenges 3 and 4 . Youth can be afforded an opportunity to design their own eyeglass frames according to their preferred shape, decoration and color. The experiments described below aim to provide a proof of concept for overcoming these four challenges with open-source distributed manufacturing.

\section{Experimental}

The entire software and hardware tool chain for the design and fabrication of the glasses used opensource technology, starting with a desktop computer running Debian 7.1 (http://www.debian.org). The glasses were designed using OpenSCAD 2013.06 [46], 
which is a free open-source CAD scripting program that generates and manipulates 3D objects. The glasses were designed to be parametric by declaring variables and then using them throughout the code. To make changes in the design (e.g. head width), the relevant variable is changed and the entire design is scaled immediately and can be exported as a 3-D model in the form of a .STL file. These files are sliced using Cura 13.06 [47], an open-source slicing program that converts the 3-D model into g-code. Finally, the gcode is then printed using the open-source RepetierHost Linux 0.90C [48] printer controller. The glasses were printed in polylactic acid (PLA) on a MOST version of the open-source RepRap Prusa Mendel [49]. This version of the RepRap uses a Bowden extruder mounted to a J-head to increase print speed. The J-head takes filament and heats it to its glass temperature, extrudes it onto blue painter's tape to form a shape, and then is moved up two hundred microns to deposit the next layer of the design. In this way, the glasses are able to be printed in under an hour and can be customized both in design, color, fill density and to fit each person based on head width and the distance between pupils.

\section{Results}

The results of the three case study designs are shown in Figures 4, 5 and 6. Figure 4 a) displays the 3-D design and b) a digital photograph of self-refractive glasses using the Adspec lenses with the first gener- ation syringe system. The new design and community printing capability allows for users to choose the preferred color of their glasses, to mix colors within parts or print parts of different colors, and to customize parts of the designs while in the community, as shown in Figure $4 b$.

In order to reduce cost further while improving aesthetics the external syringes can be replaced by a tube and pump system so that individuals can still adjust the lens after the initial screening. These tubes can be printed and personalized as shown in Figure 5 a) the 3D design, b) details the customized version of printed glasses. This design maintains the advantage of being able to adjust the glasses as light conditions or eye fatigue of the user change throughout the day. This ability to make dynamic adjustments, however, comes at the aesthetic cost of maintaining a fluid reservoir on the wearer's glasses. Although it should be noted it is possible to have a detachable reservoir.

There is a significant aesthetic challenge of designing glasses to fit perfectly circular lenses. To overcome this challenge at the expense of the continual adjustments, the glasses were redesigned to allow for one adjustment and then remove the syringe. In addition, using this scheme, as can be seen in Figure $6 a$ it is possible to print goggles that fit the standard lenses. This approach may not be socially acceptable in all communities, but it provides distinct functional advantages in areas prone to dust or sand storms. This design is shown in Figure 6a, image in 6b.
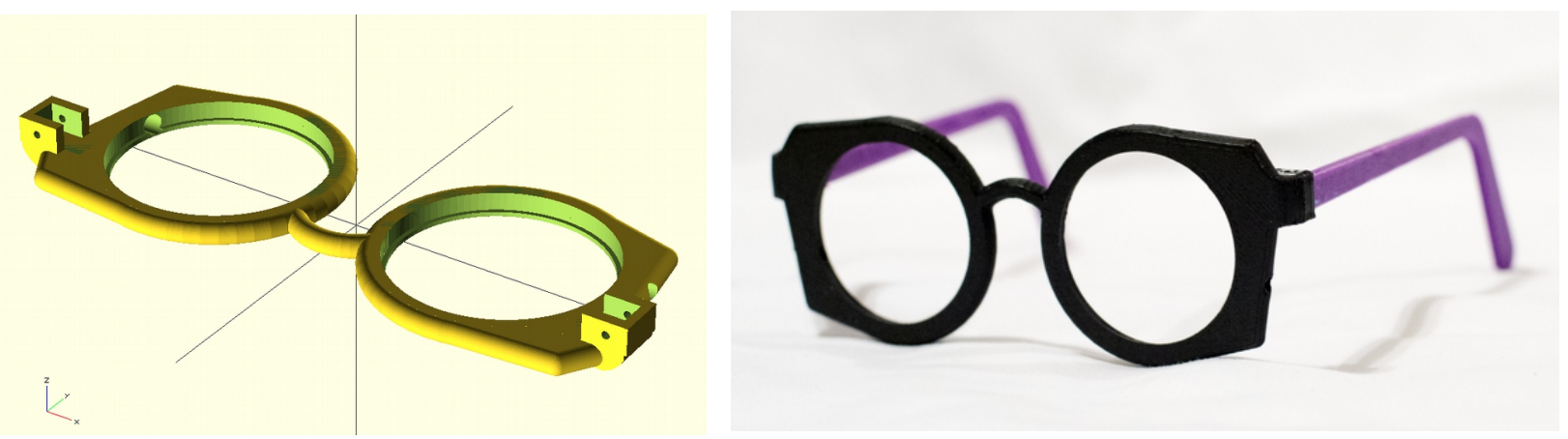

Figure 4. a) 3-D design of self-refractive glasses using the Adspec lenses and first generation syringe system, b) digital photograph of the design which has a customizable component (e.g. color choice of the user).
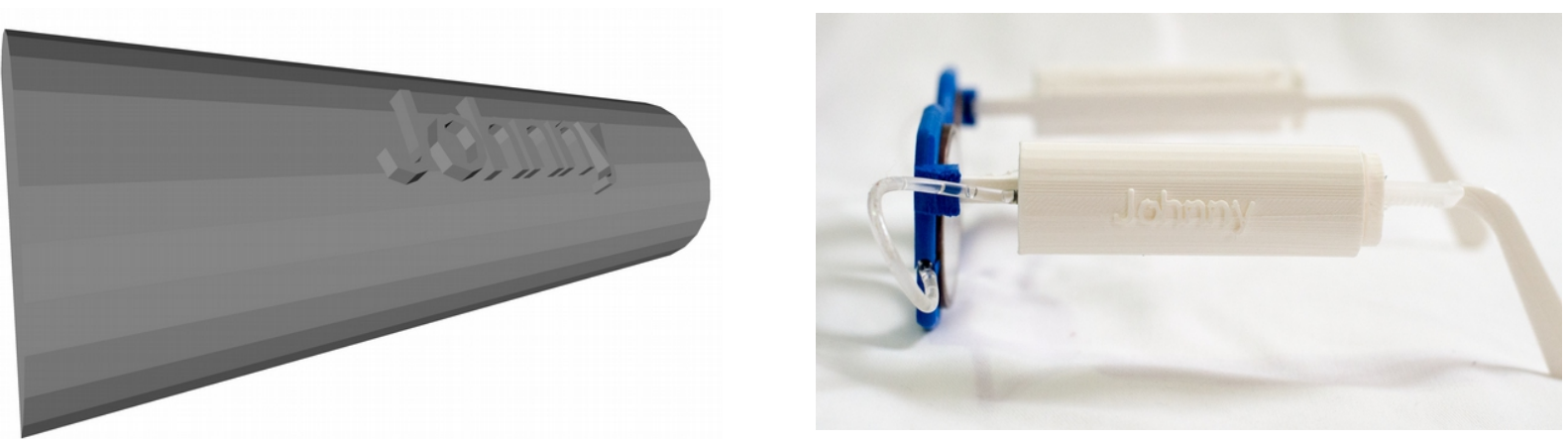

Figure 5. a) 3-D design of self-refractive glasses using a tube and peristaltic pump with standard Adspec lenses, b) digital photograph of the customizable component of the design. 
All of the designs in Figures 4-6 are developed in OpenSCAD in a fully parametric manner so they can be used with the Thingiverse Customizer Application. This enables user/designers to custom fit the glasses for themselves, as well as choose personalized aesthetically pleasing extras to be printed into their glasses without the necessity to understand CAD. The Customizer interface is shown in Figure 7. As can be seen in Figure 7a, user/designers can set measurements specific to themselves, such as head width and dis- tance between pupils. In addition, as can be seen in Figure $7 \mathrm{~b}$ all of the other parameters, such as the stem length, width, thickness and dimensions around the hinge can be adjusted to meet user preferences.

The material costs for the 3-D printable designs shown in Figure 4-6 are shown in Table 1. As can be seen in Table 1 both the goggles and the standard glasses without the syringe can be printed in under 1 hour for about one U.S. dollar using conventional commercialized filament and U.S. electricity costs.
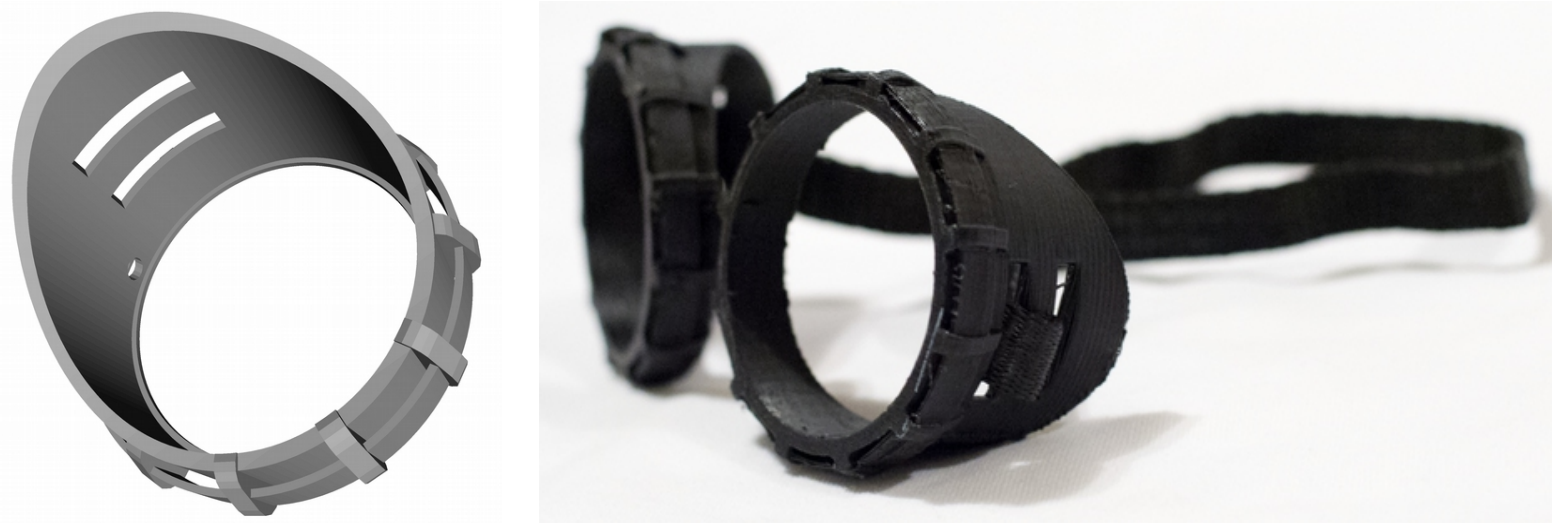

Figure 6. a) 3-D design of self-refractive goggles using a removable syringe clip system with standard Adspec lenses, b) digital photograph of the design.

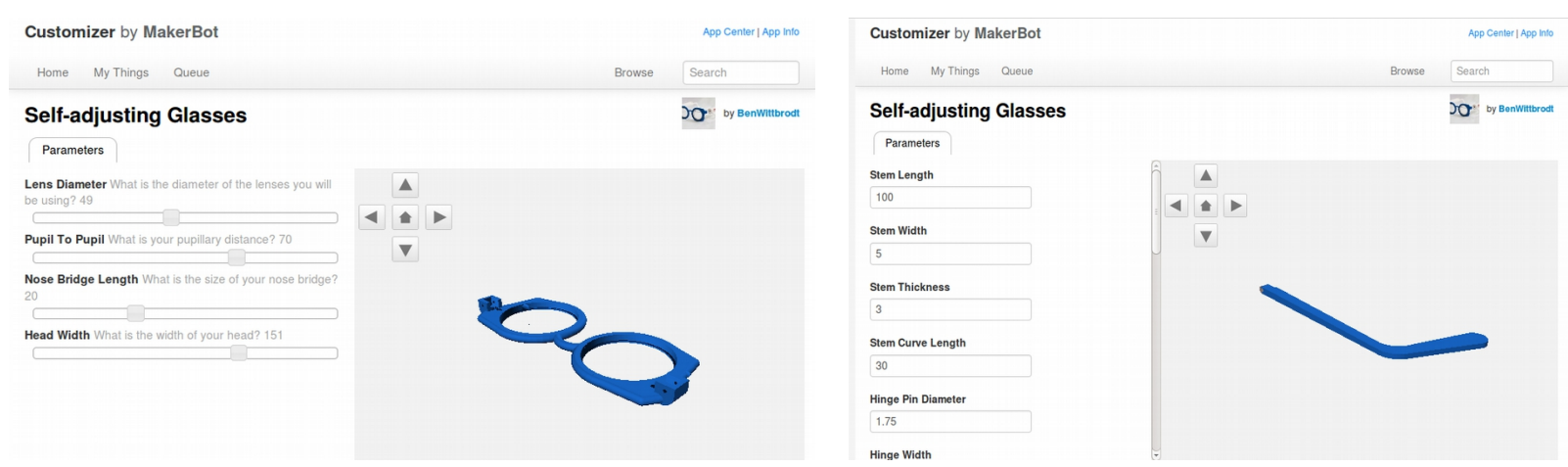

Figure 7. Screenshot of thingiverse customizer application used for customizing the 3D printable selfadjusting lenses glasses for $a$ ) the front of the glasses and $b$ ) the stems.

Table 1. Mass, print time, polymer costs, and total cost of 3-D printable designs using commercial filament and standard printing procedures [23].

\begin{tabular}{lllll}
\hline Part & Mass $(\mathrm{g})$ & Print Time $(\mathrm{min})$ & Cost of plastic $(\$ 35 / \mathrm{kg})$ & $\begin{array}{l}\text { Total Cost including } \\
\text { electricity at US ave. rates }\end{array}$ \\
\hline Lens holders & 15.82 & 28 & $\$ 0.55$ & $\$ 0.57$ \\
$\begin{array}{l}\text { Stem (each) } \\
\text { Stem with syringe }\end{array}$ & 5.86 & 9 & $\$ 0.21$ & $\$ 0.22$ \\
$\begin{array}{l}\text { (each) } \\
\text { Goggles }\end{array}$ & 24.17 & 37 & $\$ 0.85$ & $\$ 0.88$ \\
Glasses & 29.94 & 53 & $\$ 1.05$ & $\$ 1.08$ \\
Glasses with syringe & 64.16 & 102 & $\$ 0.97$ & $\$ 1.00$ \\
\hline
\end{tabular}




\section{Discussion}

The technical evolution of the self-adjustable lenses has progressed quickly, improving the quality while reducing the cost and scaling distribution. The new version of the Adspecs [50], which is being massmanufactured and distributed now, is both more aesthetically pleasing and solves some of the technical deficiencies of the first generation shown in Figure 3.

\subsection{Economic Costs}

Cost is still the primary impediment to further scaling and complete saturation of the need for the glasses in the developing world. The results presented in this study show that distributed manufacturing of some of the components of the glasses with 3-D printers could further assist achieving Vision 2020, as they enable individual customizable components at the local scale at a lower price making the self-adjusting glasses potentially affordable to those living in poverty. Utilizing distributed 3-D printing will also allow for rapid replacement of failed parts, since any part can be produced in under an hour. Currently, a part would need to be ordered and time would be lost waiting for a replacement and a potential added cost in shipping of the new part. Using distributed $3 \mathrm{D}$ printing methods also offers greater flexibility in the choice of materials with desired properties and characteristics on the individual scale. The flexibility of open-source 3-D printers in materials selection also offers the potential to reduce the costs further. As can be seen in Table 1 the primary cost is that of the plastic commercial filament. Opensource hardware called 'Recyclebots' has already demonstrated that waste plastic can be converted into usable 3-D printing filament at a cost of $\$ 0.10 / \mathrm{kg}$ in electricity at U.S. utility rates [51]. Filament costs used in Table 1 were the average of $\$ 35 / \mathrm{kg}$. Thus, this approach has the potential to reduce the costs shown in Table 1 to under a single U.S. penny for any design, essentially overcoming the cost barrier and making distributed production far less expensive than centralized manufacturing.

\subsection{Limitations of the Approach}

There are, however, several limitations to the proposed technology. This approach is currently limited by the state of development of open-source 3-D printing. Although RepRaps have been shown to print in a variety of materials, including metal [52], they are still not yet able to print the lenses (the most critical component of the eyeglasses) themselves. Further technical work is thus needed to be able to print all parts of the self-refraction glasses including the optics, as opposed to current prototypes in which only the frames and syringe are printed.

Although cost is a crucial part of the equation for full utilization, aesthetics is another challenge that should not be overlooked. In this regard, further work is needed to make printable, more aesthetically pleasing or 'cool' glasses. It is hypothesized that having students help in the design of their own glasses will help assist in this cool-factor, but that hypothesis must be tested by experiment.

Further work is needed in optics and 3-D printing to be able to overcome the current limitation of the need for circular lenses. The ability to vary lens shape and size will make it less challenging to meet the temporary, geographical and clique shifting sociallyacceptable requirements determined by the world's teenagers. Finally, community capacity development and skills appraisal workshops could assist in providing for the sustainability of the community-run/owned 3-D printing facilities.

\subsection{Sustainability of Distributed Manufacturing}

Although the environmental damage caused by the manufacturing of glasses is relatively small compared to other manufacturing sectors, this work provides a model for improving the sustainability of manufacturing not only of glasses, but also other products. Recent studies have shown a number of benefits that can be derived from adopting 3-D printing technologies, in particular environmental benefits [24]. The previous study showed that with RepRap printing using solar photovoltaic power the distributed manufacturing always has a lower environmental impact as compared to conventional manufacturing of polymer products [24]. Prototypes of solar powered 3-D printing systems have already been demonstrated for semi-mobile school-based systems, and a highlymobile system capable of fitting in a suitcase [53]. The latter system could be used to provide the glasses solution to any rural school which can be accessed by travelers bringing standard luggage. The former design is meant to become a permanent fixture at rural schools that are not connected to the electrical grid. Thus, the solar-powered 3-D printer can be used first to provide glasses for the students and other community members that need them, and then it can be used to manufacture other high-value products, such as scientific tools (for both education and use in, for example, medical clinics) [54]. In all these cases any products would have a lower environmental impact than conventionally manufactured products, even if made locally. Realistically, most specialized products would be manufactured in a centralized facility far from the users and the embodied energy of transportation would be substantial [55]. Thus, solarpowered distributed manufacturing allows off-grid rural communities to leapfrog to a more sustainable method of production. For on-grid communities using the same source of electric power, if the fill density of the 3-D printed plastic product is below $79 \%$ fill density then the environmental impact of the 3-D printed object remains lower than conventionally 
manufactured goods [53]. Some of the components to the glasses do not need to be printed at $100 \%$ fill to maintain mechanical integrity and would thus offer this sustainability benefit as well. Many consumer products can be printed for less than $20 \%$ fill density [23], thus significantly improving sustainability for any of the RepRap 3-D printers used at the schools to fabricate other products.

However, there is a lack of data on long term field performance of 3-D printed products. The finished products need to undergo field evaluation for both ruggedness and social acceptability by selected representative samples mainly from the developing world communities. Results from the field tests may be used to further improve the 3-D designs for this project. In addition, this data could be used to perform a complete life cycle analysis of the products and compared to conventionally-manufactured products. The stability and life-time of the materials used need to be documented and the recycling plan of old and disused products be put in place within communities. Again, just as the Recyclebot technology [51] would significantly improve the economics, it would have a similar positive effect on the environmental impact [56]. Thus, broken or simply old glasses could be ground up and turned back into 3-D printer filament to be turned back into glasses or other products.

\subsection{Lateral Scaling}

The feasibility of the approach to reach a large scale and thus millions of people all over the world is dependent on what Rifkin calls lateral scaling [57]. In this model of production and distribution, schools all over the developing world will operate a RepRap 3-D printer in relative isolation with no centralized management or logistics. The construction and maintenance of RepRap printers has been demonstrated by amateurs thousands of times all over the world. Specifically, in the U.S., teachers are trained to build and maintain RepRaps in training workshops. A team of two inexperienced teachers can build a delta style RepRap printer in a day. As a true RepRap, this printer could then be used to manufacture the specialized plastic components of both itself and other printers to spread the technology throughout the region. This model could be adopted in the developing world at very low cost points, as the RepRap knowledge materials (for constructing, maintaining and printing) are all available for free on line.

The data in Table 1 can be used to evaluate what this would look like in an individual school or community with a single RepRap, which costs less than US\$500 in parts, all of which are available for purchase on the Internet. With either the glasses or goggles using approximately $30 \mathrm{~g}$ of plastic a single US\$35 kg spool of filament would be able to correct the vision of 33 children. If the syringes were printed as well this would be only 15 children per $\mathrm{kg}$ spool. Again, as mentioned above, if the spools were Recyclebot plastic, the costs would be less than $\$ 0.01$ per student served. To continue to operate the printer, the school would need access to either the purchase of plastic online or locally or the ability to turn waste plastic into filament. The staff to operate the printer could be trained in workshops or learn online for free. Ideally, the students themselves would learn to operate and maintain the printers as part of their education. If the 3-D printer at a school was staffed 8 hours per day and was only used to make glasses it could produce 8 pairs per day or 5 pairs with the syringes per day (note: that the final print of the day can be set up and left unattended thus effectively increasing printing time beyond 8 hours/day). Thus, roughly $1 \mathrm{~kg}$ of plastic would be consumed per school week of continuous production of glasses. Thus, if operated for an entire year only printing glasses, a single RepRap could produce 2,080 pairs of glasses and Sconsume about $52 \mathrm{~kg}$ of plastic.

The primary application of this solution would involve base design code (e.g the OpenSCAD scripts) being untethered from the web and transported manually with the 3-D printer along with the necessary plastic to provide glasses given a school's population. Thus, only the imagination of the student population and electricity would need to be supplied. In the case of electricity this would be provided on site either from the grid, generators, batteries or the previously discussed solar panels, depending on the community's circumstances. This is a start, however, in many locations now and in a growing number of developing world communities, Internet access will enable more sophisticated and rapid design browsing and cloud-based design could play a greater role. Cloud manufacturing, is a service oriented, customer centric, demand driven manufacturing model [58]. It could be used by entrepreneurs in developing world communities (e.g. to collaborate on designs, provide design services for sale, and even perhaps to manufacture items for sale in both their communities and elsewhere $[59,60])$. Again, in the ideal case, these revenue streams could provide a return on the investment of the initial capital needed for the RepRap, Recyclebot and filament to get started, and provide the necessary vision correction with self-refraction eyeglasses for students and local residents. The additional technical skills in the community and the ability to manufacture low-volume high-value products in an environmentally sustainable way would be a significant benefit. The technology discussed here is only a single example of how open-source 3-D printers could provide high-value products to communities in the developing world at very little cost as there have been many proposals for other appropriate technologies and scientific tools $[18,53]$. 


\section{Conclusions}

Although the trend in manufacturing has been towards centralization, the technical development of the open-source 3-D printer enables low-cost distributed bespoke production. This paper demonstrated some of the potential advantages of a distributed manufacturing model of high-value products by investigating self-refraction eyeglasses. By utilizing 3-D printable self-adjustable glasses the target market not only gains access to far more diversity in product design, but also offers the potential for significant costs reductions for obtaining functional corrective glasses. The results showed that the primary cost of the glasses could be reduced to about one dollar for a highly customized/individualized design, which could be printed on site in under an hour. Distributed manufacturing with 3-D printing can empower these com-

\section{References}

[1] Hounshell DA. From the American System to Mass Production, 1800-1932: The Development of Manufacturing Technology in the United States. Baltimore, MD, USA: Johns Hopkins University Press; 1984.

[2] Osborn GA. The Crimean War gunboats, part 1. The Mariner's Mirror, the Journal of the Society of Nautical Research. 1965;51(2):103-116.

[3] Williams D. Mass-Produced Pre-Han Chinese Bronze Crossbow Triggers: Unparalleled Manufacturing Technology in the Ancient World. Arms \& Armour. 2008;5(2):142-153.

[4] Miltenburg J. Manufacturing strategy: How to formulate and implement a winning plan. New York, NY, USA: Productivity Press; 2005.

[5] Mukherjee S. Modern Economic Theory. New Delhi, India: New Age International Publishers; 2007.

[6] Pearce JM. Industrial symbiosis for very large scale photovoltaic manufacturing. Renewable Energy. 2008;33(5):81101-81108.

[7] Kravis IB, Lipsey RE. The location of overseas production and production for export by U.S. multinational firms. Journal of International Economics. 1982;12(3):201-223.

[8] Ruamsook K, Russell D, Thomchick E. U.S. sourcing from low-cost countries: A comparative analysis of supplier performance. Journal of Supply Chain Management. 2007;43(4):16-30.

[9] Rodrigue J, Notteboom T. The geography of transport systems. 3rd edition. New York, NY, USA: Routledge; 2013.

[10] Pearce JM, Johnson SJ, Grant GB. 3D-Mapping Optimization of Embodied Energy of Transportation. Resources, Conservation and Recycling. 2007;51(2): 435-453.

[11] Chituc C, Restivo FJ. Challenges and Trends in Distributed Manufacturing Systems: Are wise engineering systems the ultimate answer? Second Inter- munities through the ability to print less expensive and customized self-adjusting eyeglasses, displacing conventional glasses and giving a viable option to the world's most impoverished population who generally cannot afford the cost of expert optics correction (e.g. optometrist, ophthalmologist, or even conventional lenses). Here only a single product was analyzed, but it seems clear that other products would benefit from the same approach and that distributed manufacturing can assist in sustainable development, particularly in isolated rural regions.

\section{Acknowledgements}

The authors would like to acknowledge helpful discussions with J. Silver and G. Anzalone and support from the Fulbright fellowship program.

national Symposium on Engineering Systems, MIT, Cambridge, MA, USA, 2009. pp. 15-17.

[12] Rhodes D, Hastings $D$. The case for evolving systems engineering as a field within engineering systems. 1st MIT Engineering Symposium, Boston, MA, USA, 31 March 2004.

[13] Markillie P. A Third Industrial Revolution: Special Report Manufacturing and Innovation. Economist, 21st April 2012. Available from: http://www.economist.com/node/21552901.

[14] Bradshaw S, Bowyer A, Haufe P. The intellectual property implications of low-cost 3D printing. ScriptEd. 2010;7(1):1-27.

[15] Cano J. The Cambrian explosion of popular 3D printing. International Journal of Artificial Intelligence and Interactive Multimedia. 2011;1(4):30-32.

[16] Corney J. The Next and Last Industrial Revolution? Assembly Automation. 2005;25(4):257.

[17] Gershenfeld N. Fab: The Coming Revolution on Your Desktop-from Personal Computers to Personal Fabrication. New York, NY, USA: Basic Books; 2005.

[18] Pearce JM, Blair CM, Laciak KJ, Andrews R, Nosrat A, Zelenika-Zovko I. 3-D printing of open source appropriate technologies for self-directed sustainable development. Journal of Sustainable Development. 2010;3(4):17-29.

[19] Jones R, Haufe P, Sells E. RepRap-the replicating rapid prototype. Robotica. 2011;29(1): 177-191.

[20] Arnott R. The RepRap project-open source meets 3D printing. Computer and Information Science Seminar Series. Available from: http://hdl.handle. net/10523/1531.

[21] Sells E, Smith Z, Bailard S, Bowyer A, Olliver V. Reprap: The replicating rapid prototyper: Maximizing customizability by breeding the means of production. Handbook of Research in Mass Customization and Personalization. Forthcoming; 2010.

[22] Kühnle H. Distributed Manufacturing: Para- 
digm, Concepts, Solutions and Examples. London, UK: Springer; 2010.

[23] Wittbrodt BT, Glover AG, Laureto J, Anzalone GC, Oppliger D, Irwin JL, Pearce JM. Life-cycle economic analysis of distributed manufacturing with open-source 3-D printers. Mechatronics. 2013;23(6):713-726.

[24] Kreiger M, Pearce JM. Environmental Life Cycle Analysis of Distributed 3-D Printing and Conventional Manufacturing of Polymer Products. ACS Sustainable Chemistry \& Engineering. 2013;1(12):1511-1519.

[25] Crane NB, Tuckerman J, Nielson GN. Self-assembly in additive manufacturing: Opportunities and obstacles. Rapid Prototyping Journal. 2011;17(3):211-217.

[26] Petrovic V, Gonzalez JVH, Ferrando OJ, Gordillo JD, Puchades JRB, Griñan LP. Additive layered manufacturing: Sectors of industrial application shown through case studies. International Journal of Production Research. 2011;49(4):1061-1079.

[27] WHO. Visual impairment and blindness. Fact Sheet $N^{\circ} 282$. Available from: http://www. who.int/mediacentre/factsheets/fs282/en/.

[28] WHO. Action Plan for the Prevention of Avoidable Blindness and Visual Impairment, 20092013. Available from: http://www.who.int/ blindness/ACTION_PLAN_WHA62-1-English.pdf.

[29] Resnikoff S, Donatella PD, Mariotti SP, Pokharel GP. Global magnitude of visual impairment caused by uncorrected refractive errors in 2004. Bulletin of the World Health Organization. 2008;86(1):1-80. Availaible from: http://www. who.int/bulletin/volumes/86/1/07-041210/en/.

[30] Crosby DN, Douali MG, Mackenzie GE, Plimmer MD, Taylor RJ, Silver D. Vision Correction in the Developing World. Perhaps the largest application of Adaptive Optics? The Centre for Vision in the Developing World, University of Oxford: Oxford, UK. Available from: http://www.vdwoxford.org/ resources/AO_Poster_Nov2008-v3_final.pdf.

[31] Carlson AS. Vision correction in the remote north of Ghana using the self-refraction AdSpec. South African Optometrist. 2006;65(1):41-46.

[32] Gyasi ME. Setting the pace for VISION 2020 in Ghana: The case of Bawku Eye Care Programme. Community Eye Health Journal. 2006;19(59):46-47.

[33] Fricke TR, Holden BA, Wilson DA, Schlenther G, Naidoo KS, Resnikoff S, Frick KD. Global cost of correcting vision impairment from uncorrected refractive error. Bulletin of the World Health Organization. 2012;90(10);728-738.

[34] Veatch. Veatch ophthalmic instruments. Dispensing equipment. Available from: http://www. veatchinstruments. $\mathrm{com} /$ storeitems.asp?cc=dispens ing_EQ.

[35] Maini R, Keeffe J, Weih L, McCarty C, Taylor H. Correction of refractive error in the Victorian population: The feasibility of "off the shelf" spectacles. British Journal of Ophthalmology. 2001;85(11):1283-1286.

[36] Eyebuydirect.com. Perfect vision for less. Available from: http://www.eyebuydirect.com/classic- eyeglasses.html.

[37] Tuck M. Poverty. The World Bank Group. Available from: http://web.worldbank.org/WBSITE/ EXTERNAL/TOPICS/EXTPOVERTY/EXTPA/0, contentM DK:20040961 menuPK:435040 pagePK:148956 piP K:216618 theSitePK:430367 isCURL:Y,00.html.

[38] Douali MG, Silver JD. Self-optimised vision correction with adaptive spectacle lenses in developing countries. Ophthal Physiol Opt. 2004;24(3):234-241.

[39] Silver JD, Douali MG, Carlson AS, Jenkin L. How to use an adaptive optical approach to correct vision globally. South African Optometrist. 2010;62(3): 126-131.

[40] Afenyo GD, Silver JD. Vision Correction with Adaptive Spectacles. In: Pararajasegaram R, Rao G. World Blindness and it's Prevention. London, UK: International Agency for the Prevention of Blindness; 2001.

[41] He M, Congdon N, MacKenzie G, Zeng Y, Silver JD, Ellwein L. The Child Self-Refraction Study: Results from Urban Chinese Children in Guangzhou. Ophthalmology. 2011;118(6):1162-1169.

[42] Zhang $M$, Zhang $R$, He M, Liang W, Li X, She L, Yang Y, MacKenzie G, Silver JD, Ellwein L, Moore B, Congdon N. Self correction of refractive error among young people in rural China: Results of cross sectional investigation. British Medical Journal. 2011;343:1-10. Available from: http://www.bmj.com/content/343/ bmj.d4767

[43] Smith K, Weissberg E, Travison TG. Alternative Methods of Refraction: A Comparison of Three Techniques. Optometry and Vision Science. 2010;87(3):E176-E182. Available from: http:// journals.Iww.com/optvissci/Abstract/2010/03000/Alterna tive_Methods_of_Refraction_A_Comparison_of.7.aspx.

[44] Pearce JM. The Case for Open Source Appropriate Technology. Environment, Development and Sustainability. 2012;14(3):425-443.

[45] Zhang C, Anzalone NC, Faria RP, Pearce JM. Open-Source 3D-Printable Optics Equipment. PLoS ONE. 2013;8(3):e59840.

[46] OpenSCAD. OpenSCAD 2013.06. The Programmers Solid 3D CAD Modeller. Available from: http://www.openscad.org/.

[47] Cura. Cura 13.06 user manual. Available from: http://blog.ultimaker.com/cura-user-manual/.

[48] Repetier. The software driving your 3d printer. Available from: http://www.repetier.com/.

[49] MOST. MOST RepRap Primer. Available from: http://www.appropedia.org/MOST_RepRap_Primer.

[50] Center for Vision and the Developing World. Available from: http://www.vdwoxford.org/home/.

[51] Baechler C, DeVuono M, Pearce JM. Distributed Recycling of Waste Polymer into RepRap Feedstock. Rapid Prototyping Journal. 2013;19(2): 118-125.

[52] Anzalone GC, Zhang C, Wijnen B, Sanders PG, Pearce JM. Low-Cost Open-Source 3-D Metal Printing. IEEE Access. 2013;1:803-810.

[53] King DL, Babasola A, Rozario J, Pearce JM. 
Development of Mobile Solar Photovoltaic Powered Open-source 3-D Printers for Distributed Customized Manufacturing in Off-grid Communities. Challenges in Sustainability. 2014;2(1):18-27.

[54] Pearce JM. Open-source Lab. New York, NY, USA: Elsevier; 2014.

[55] Pearce JM, Johnson SJ, Grant GB. 3D-mapping optimization of embodied energy of transportation. Resources, conservation and recycling. 2007;51(2): 435-453.

[56] Kreiger MA, Mulder ML, Glover AG, Pearce JM. Life Cycle Analysis of Distributed Recycling of Postconsumer High Density Polyethylene for 3-D Printing Filament. Journal of Cleaner Production. 2014;70:90-96.

[57] Rifkin J. The Zero Marginal Cost Society: The Internet of Things, the Collaborative Commons, and the Eclipse of Capitalism. New York, NY, USA: Macmillan; 2014.
[58] Wu D, Thames JL, Rosen DW, Schaefer D. Enhancing the Product Realization Process with CloudBased Design and Manufacturing Systems. Transactions of the ASME, Journal of Computing and Information Science in Engineering. 2013;13(4): 041004-1-041004-14.

[59] Wu D, Greer MJ, Rosen DW, Schaefer D. Cloud Manufacturing: Strategic Vision and State-of-the-Art. Journal of Manufacturing Systems. 2013;32(4): 564-579.

[60] Schaefer D, Thames JL, Wellman RD, Wu D, Yim S, Rosen DW. Distributed Collaborative Design and Manufacture in the Cloud-Motivation, Infrastructure, and Education. 2012 American Society for Engineering Education Annual Conference, Paper \#AC2012-3017, San Antonio, TX, USA. 